\title{
An Analysis on the Pursuit of Happiness in The Lord of the Rings
}

\author{
Lili Liu \\ Taishan University, Taian, China
}

\begin{abstract}
Since The Lord of the Rings was adapted by Peter Jackson into trilogy film in 2001-03, it has astounded its critics and gratified its fans and students. Many critical journals or graduation papers have also talked about this massive novel. After doing a lot of reading concerning these reviews, it's clear that most of them analyze this work using psychoanalytical criticism; myth and archetypal criticism; cultural studies, and recently ecocriticism. Among these theories, psychoanalytic interpretation mainly focuses on Freud's key ideas, namely the id; ego; and superego. According to Freud's theory that: "Psychoanalytic literary criticism is not simply about interpreting a text's protagonists. It also seeks to relate the text to the mind of its author."(Berg, 2003, p.84). In this circumstance, this paper will probably dig some new insights by using this theory. The paper will follow the protagonist's inner mind through employing Freud's some key ideas, such as repression and projection. Based upon psychoanalytic analysis of the protagonists, this paper tries to argue that the three Hobbits can acquire happiness as long as they deal properly with the relationship between themselves and the society. In other words, common people can also push the wheel of history as long as they code well with themselves and the society.
\end{abstract}

Index Terms-psychoanalytical criticism, Repression, Projection, Happiness

\section{INTRODUCTION}

When considering the commentary related to The Lord of the Rings, the idea that it is a story about growing up or maturation is a popular notion, and an aspect for which psychoanalytic analysis is appropriate. Doubtless, the Ring itself reflects the development of the characters' mental processes. The three hobbits who have a close connection with it all changed considerably: first, they would grow irrational, acting contrary to convention, then return to normality before falling into desperation. Finally, they would have all kinds of fantasies, their very behavior controlled by the Ring. The plot of The Lord of the Rings can be summarized as humans being disturbed and tortured by the Ring they forged. However, we cannot confine the plot to only this level. Through the act of destroying the Ring by Frodo, the Ring-bearer, and his fellowship, we can also see people's struggle against being "conquered by the Ring."

\section{The Problems the “Queer” Hobbits Face}

According to the description in the "Concerning Hobbits" section of The Lord of the Rings, we know that hobbits are different from humans. They are simple-minded, living a happy life in the peaceful Shire. The issue of social and cultural differences in the Shire actually reveals a dangerous situation among its inhabitants. Gandalf, who always holds the correct perspective, worries that Sauron will enslave the charming, absurd, and helpless hobbits. Moreover, the hobbit families are eager to obtain power either absurdly or significantly. Their awareness of differences in the Shire allows Frodo, who has a special ability, to become the potential person to accept the mission and attract followers.

It is because of the Shire's isolation from the rest of Middle-earth that many political problems arise among its inhabitants, and "queerness" is a prominent reason for these problems. The hobbits cannot believe those who come from outside because they behave and think in ways the hobbits cannot understand. For example, they exhibit a distrustful attitude toward Dark Rider when he suddenly appears in the Shire. They also tend to enjoy acting similarly in ways that include living in holes, eating excessively, and smoking tobacco, so when Bilbo and Frodo obtain a treasure, a mark of distinction, the hobbits present a hostile attitude toward them. Therefore, in order to maintain the inhabitants' trust, one must make oneself "natural" and diminish one's "queerness."

Bilbo is "very rich and very peculiar." to the extent that some inhabitants begin to be jealous: ...it seemed unfair that anyone should possess perpetual youth as well as inexhaustible wealth" (Tolkien, 1999, p. 27). Both his wealth and longevity make him seem "queer": "It isn't natural, and trouble will come of it!" (Tolkien, 1999, p.27). On the one hand, the "trouble" derives from Bilbo's wealth and long life, which arouses the inhabitants' jealousy. On the other hand, Bilbo is queer to his fellowship in the Shire because he has been changed by the journey, obtaining considerable knowledge about the world. In addition, control of the Ring made him conscious of good and evil. For one thing, the desire of the self wants to possess the Ring. For another, Bilbo wants to protect the Shire and the world from Sauron's slavery; a contradiction that has made him thin. Moreover, when a person wears the Ring, they become invisible. This is because, when the Ring controls its wearer, it erases their identity: one has lost their self. In the novel, Bilbo has remained young but become thin and stretched. However, he has never connected this to his possession of the Ring. In 
fact, to obtain control of an individual, the Ring appeals to the desire of the self for gold, power, and love as a means of controlling the individual.

Aiming to win support from the inhabitants, both Bilbo and Frodo take a generous attitude toward them. Bilbo shares his money with his friends and relatives: "He had many devoted admirers among the hobbits of poor and unimportant families" (Tolkien, 1999, p.27). Indeed, his generous actions diminish the fear of difference among the less wealthy hobbits. People in the Shire think he is "well-spoken," polite, and gentle because he treats them in a fair manner, without demonstrating a superior attitude. However, in order to gain the support and trust of the hobbits, Bilbo must address two problems. First is the arrival of Frodo, an orphan and his heir, which arouses the potential inheritor's anger, since their inheritance will be significantly decreased. Second is the inheritance of Bag End by Frodo due to Bilbo's disappearance on his birthday party. Since the relatives continue to be entangled with the "treasure" Frodo receives, he will inherit the problems Bilbo used to face.

Realizing this problem, Bilbo must act. At this moment, Bilbo's ego starts to play a part. It takes charge of the spiritual aspect of one's personality, such as logic, learning and observation" (Freud, 1992, p.15). It always attempts to maintain a balanced relationship between desire and conscience, functioning as a coordinator of the personality. The ego's obligation is to protect an individual's life from all dangerous situations in the outside world (Freud, 1992, p.17). Bilbo organizes a party, inviting all the inhabitants of the Shire, and all who attend receive a present. He also offers them the splendor of fireworks, songs, dances, music, games, and fine and abundant food. The moment Bilbo disappears from public signifies the disappearance of selfishness. By offering a remarkable birthday party and suddenly disappearing from it, Bilbo succeeds in achieving a harmonious relationship with the inhabitants.

The peculiarity of the Ring offers its wearer special power. It promotes the self and allows the individual to have the prospect of power. Perhaps it is because of the Ring that Bilbo was queer to others. At first, Bilbo is not willing to relinquish the Ring to Gandalf. In his eyes, other people are unworthy of trust. He says to Gandalf: "Now it comes to it, I don't like parting with it at all, I may say. And I don't really see why I should. Why do you want me to?' he asked, and a curious change came over his voice. It was sharp with suspicion and annoyance. 'You are always badgering me about my ring: but you have never bothered me about the other things that I got on my journey"' (Freud, 1992, p.43). Bilbo wants to keep the Ring because he found it: "It is my own. I found it. It came to me" (Freud, 1992, p.43). It is the gift Bilbo most needs to be rid of. However, when Gandalf insists that Bilbo should leave the Ring with Frodo, he uses the same language as Gollum: "It is mine, I tell you. My own. My precious. Yes, my precious" (Tolkien, 1999, p.44). At this moment, Bilbo's id takes control of his personality, wanting only to fulfill his desire of possessing the Ring. However, the constraint of reality makes his ego work, forcing him to part with the Ring.

In order to free himself, Bilbo must stop possessing the Ring. However, it is extremely difficult for him to do so. Gandalf's demand for the Ring arouses Bilbo's suspicion, and he treats Gandalf as a thief. Then Gandalf wins his trust back by saying, "I am not trying to rob you, but to help you. I wish you would trust me as you used" (Tolkien, 1999, p.45). Bilbo apologizes: "But I felt so queer... And I don’t seem able to make up my mind" (Tolkien, 1999, p.45). Bilbo must have realized his queerness comes from his wealth, perpetual youth and generosity, which permits him to hold a prominent position in the Shire. Therefore, it is difficult for him to give up the Ring. "Giving up the Ring is the final gift: to allow the self to grow and mature, the individual must learn to be selfless" (Bloom, 2008, p.23). In this case, Bilbo's generous behavior toward his relatives is correct and necessary.

Bilbo's deed of giving the Ring to Frodo has the same function. When Frodo gains the Ring, however, it represents a prospect for individual and even heroic maturation. Unlike a traditional quest that aims to pursue profound knowledge or valuable treasure, Frodo must destroy something. According to the previous description, Bilbo must change his ego and be generous toward the inhabitants of the Shire to become the same as them. However, returning the Ring to its owner means that one must renounce the possession of power. Therefore, Frodo, who is different from other hobbits and his queer cousin Bilbo, is more suitable for the quest.

Unlike Bilbo, who has deep roots in the Old Forest, Frodo is accepted by the hobbits in the Shire perhaps simply because of the wealth and favor his cousin offered. However, Frodo is as "queer" as Bilbo. Frodo is an orphan from "across the river" (a similar experience as his creator (Tolkien; Bloom 23). His people like using boats, which makes the hobbits feel he is unnatural.

After Bilbo disappears, Frodo becomes the Lord of the Manor and must face a test from the Sackville-Bagginses. They not only buy things not given away at a lower price but also spread the rumors that Gandalf and Frodo plan to obtain Bilbo's wealth. Frodo can tolerate their unfriendliness since he is accompanied by his cousin Merry Brandybuck who, like his mother, comes from Buckville near the Old Forest. At first, Frodo regards Bag End as his inheritance to keep. As time passes, however, Frodo reveals his "oddity" just as Bilbo did, by holding birthday parties for his cousin. His best friends are Merry Brandybuck, Peregrin Took, and other younger hobbits who are fond of Frodo. Like Bilbo, Frodo can maintain his youth due to his possession of the Ring and is therefore considered "queer" by the Shire inhabitants.

There is little doubt that tension exists between the "normal" and "queer" hobbits. This kind of difference can surely lead to trouble and danger. However, in Tolkien's perspective, difference can lead to coldness (Frodo stealing mushrooms and venturing into others' lands), adventures (both Frodo and Bilbo setting out on their journeys), and finally wisdom and understanding. We can also feel differences in social relationships. While hobbits from a lower class 
generally engage in manual labor, such as gardening and domestic service, Sam helped Frodo up Mount Doom and helped him destroy the Ring, rendering him noble and worthy of respect from others in the final chapters. The same situation is true for Gollum. He was an unsettling creature, casting avaricious eyes on the Ring without considering other factors. However, Gollum's moral deficiency is ameliorated by his final contribution to civilization and cosmic good when he disobeys his "master," Frodo, and steals the Ring. Because of this deed, Frodo can finally relinquish control of the Ring and obtain the happiness he pursues.

Gollum is descended from a branch of hobbit-kind "akin to the fathers of the fathers of the Stoors" (Tolkien, 1999, p.69). Together with other hobbits, they should have shared a similar culture. However, Gollum has forgotten much of it as a result of his solitary lifestyle. This is the reason why Gollum is quite different from the other hobbits. In some sense, he stands as an alter ego for Bilbo-Frodo. Like Frodo, Gollum treats the Ring as his "birthday present" because it was given to him on that special day. Frodo initially treats Gollum similarly to the manner in which the Brandybucks treat him, reacting to Gollum's "queerness" with suspicion and anger. Therefore, at first, he states that Gollum should have been killed, saying to Gandalf: "What a pity that Bilbo did not stab that vile creature when he had a chance" (Tolkien, 1999, p.78). He cannot understand that it is Bilbo's pity and mercy that, even while wearing the Ring, offers him a happy life, and, ironically, it is Gollum on the lip of Mount Doom who saves Frodo and indeed Middle-earth itself.

In Tolkien's perspective, differences serve each other: "the relationship is circular and depends upon both need and desire, necessity and obligation, the dances of Self and Other until the music ends" (Bloom,2008,p.25).

The above section primarily analyzes the social and cultural problems the "queer" hobbits face. This section consists of background information regarding the characters' changes in attitude and behavior when addressing complicated situations, further probing their inner minds from a psychoanalytical point of view.

\section{The RING's CONTROL: THE WARPING OF HUMANITY}

The Ring's control and enslavement of human beings is revealed through spiritual manipulation. Through subconscious power leaking into people's minds, the Ring changes people's spiritual perceptions gradually, then makes them identify with it, finally achieving the aim of controlling human beings. Desire is a part of what the Ring represents, and it is a power people cannot resist. Possessing the Ring means that the individual loses a sense of who they are and what they truly want.

Freud's early theory assumed that "hysteria stems from libido's over-control and inappropriate over-release" (Baronet, 2006, P.76). He subsequently modified this theory, suggesting that, "hysterics were suffering from reminiscences; that is, that their symptoms were the results of the continued mental tension produced by traumatic events" (Yang, 2000, p. 82). In fact, characters in The Lord of the Rings have hysterical feelings concerning losing the Ring.

In some sense, Bilbo was the first person who owned the Ring. When he meets Gandalf at his birthday party, he says to his old friend that, "I am old, Gandalf. I don't look it, but I am beginning to feel it in my heart of hearts. Well-preserved indeed! Why, I feel thin, sort of stretched, if you know what I mean: like butter that has been scraped over too much bread" (Tolkien, 1999, p.42). Words like "thin" and "stretched" clearly reveal the considerable spiritual pressure weighing on Bilbo. This kind of tiredness derives from his anxiety concerning losing control of the Ring.

The same phenomenon also happened to Bilbo. At "the Council of Elrond," when asked to deliver the Ring, "Bilbo was shaken by a sudden shame and fear; and he felt a great reluctance to reveal the Ring, and a loathing of its touch. He wished he was far away." (Tolkien, 1999, p.321) Words such as "shame," "fear," and "loath" illustrate Bilbo's fear and anxiety, and it is clear that Frodo's anxiety derives from the Ring. He is afraid of losing the Ring. Therefore, he is unwilling to let other people see it, fearing that they will steal it from him. At that moment, the Ring is by no means just an ordinary object. It has mixed with the self's emotion: the fulfillment of the self's desire. Losing the Ring means the self has nothing to pursue, which rendered him hysterical. However, fear is an extreme aspect of hysteria, used by the self as a barrier to avoid connecting with the outside world. Therefore, we can say that, because of the Ring's effect, Frodo began to unconsciously establish a barrier to guard against his fellowship. Depression is the self's defensive mechanism in psychoanalysis. Freud thinks that, “as long as id, ego, and superego's drain confront with anti-drain's resist, it will not go into the mind. The suppression and dissolution of drain to anti-drain means depression" (Wang, 1998, p. 79). In the novel, fear of losing the Ring makes the hobbits feel shameful or embarrassed. However, they cannot resist this desire, so depression comes into being. In this sense, hysteria and depression occur together. In the story, when Bilbo and Frodo sense their depression, they always try to control that feeling. However, since the evil power of the Ring is so substantial, they fail to change this situation, resulting in odd behavior.

To sum up, the sudden malevolent face of Bilbo and the shadow in Frodo's mind are the evil power's projection onto their unconsciousness. Once the self-defense mechanism fails, their minds are manipulated by the Ring, driving them to unusual acts.

"Projection occurs when an unwanted thought, feeling or motive is attributed to another person and is closely connected to denial, which is the process by which the individual denies feeling a particular emotion, but asserts that someone else does!" (Tolkien, 1999, p.46). In the novel, when the characters who are controlled by the Ring fail to self-repress, daydreaming and a split self occurs. When an individual's desire cannot be achieved, it will transform into the above two forms.

As soon as Frodo puts the Ring on, it starts to gradually affect him. In Elrond, although Frodo has been controlled by 
the Ring, and his humanity has begun to change, he can resist himself at this moment. However, when closer to Mordor, the Ring's power grows increasingly stronger, and Bilbo has difficulty resisting its corrosion, and his humanity begins to degenerate.

Events on the Anduin River represent a vital point in the plot's development. Boromir, a prince of Gondor, is tempted by the evil Ring. He wants to take the Ring to his people, making his country flourish again. To escape Boromir's attempted theft, Frodo puts the Ring on and is invisible to the outside world. This conflict between Boromir and Frodo not only makes the fellowship fall into crisis, but also forces Frodo to leave the fellowship and continue the quest without help, facing perils alone. It is worth noting that, when wearing the Ring this time, he sees Sauron's fantasy and the eye for the first time. Those fantasies were daydreams Frodo had. Freud believed that, "daydreams resulted from Libido, since happy people would not have daydreams, only those who haven't achieved their wishes would daydream." Therefore, when Frodo sits on the throne overlooking Middle-earth and foresees the future, it indicates that he is no longer satisfied with being just an ordinary hobbit, and that he wants to become a ruler, controlling the whole world. The lustful "eye" is an embodiment of his own desire. The appearance of the fantasy indicates that Frodo cannot resist the evil power in his unconscious mind and begins to be manipulated by it.

The opposition of Gollum and Smeagol also presents the conflict between the Ring's will and the controlled. "division of ego." Ever since Gollum is presented in the novel, two voices always accompany him. Gollum represents the Ring's will, while Smeagol represents the self before degeneration as a natural, ethical and pure body. The quarrel between Gollum and Smeagol is an external form of the self and a power struggle. Since Smeagol could not control the evil ego in his unconscious mind, it would be presented as a single individual to fight against the main body. Therefore, whether Gollum acts rightly or wrongly all depended on what kind of mind controlled him. When promising to lead Frodo to Mount Doom, Smeagol's mind is dominant at that moment. Gollum follows Smeagol's every instruction. However, when Smeagol's kindness is suspected by Sam, Gollum takes the place of Smeagol's predominance. "the fleeting moment had past, beyond recall. 'Sneaking, sneaking!' he hissed. 'Hobbits always so polite, yes. O nice hobbits!' Smeagol bring them up secret ways that nobody else could find. Tired he is, thirsty he is, yes thirsty; and he guides them and he searches for paths, and they say sneak, sneak. Very nice friends, O yes my precious, very nice"' (Tolkien, 1999, p.936). Gollum speaks this not only for the purpose of defending Smeagol, but also to persuade Smeagol to give up his predominance, allowing the evil mind to take control.

All in all, both Frodo's fantasy and Gollum's split self all indicate that the Ring tries to manipulate characters' minds and change their wills.

In psychoanalysis, "recognition" means objectivity takes the predominant position, and subject changes to adapt to objective's change" (Yang, 2000, p.111-112). In the novel, the characters spiritually rely on the Ring, and gradually lose their own consciousness, which could be called recognition.

In Elrond, Frodo had a clash with Bilbo. Next, on the way to Moria, Frodo lost his spiritual leader. Finally, he departed from his fellowship on the Anduin, facing various on-coming dangers by himself. All through the journey, Frodo's friends diminished in number, and he felt increasingly lonely. The first time he felt lonely was in Elrond. It is also the first time he began to repel and be suspicious of his friends. Loneliness in Elrond was a presentation of Frodo's empty mind. The Ring made him have misunderstandings with his friends, and he closed his heart toward them. Therefore, although many friends were around him, he felt even lonelier. In Cirith Ungol, Frodo estranged his only friend, Sam, which led him into absolute loneliness. When the Orcs tortured Frodo, not only was his body wounded, but his will was also destroyed. When Sam brought the Ring and gave it back to Frodo, Frodo snatched the Ring and chain from Sam's hands. "The hideous vision had seemed so real to him, half bemused as he was still with wounds and fear. Sam had changed before his very eyes into an orc again, leering and pawing at his treasure, a foul little creature with greedy eyes and slobbering mouth" (Tolkien, 1999, p.1193). Fantasy is a daydream. It means a lack of desire, and only happens to people who have not achieved their goal. Therefore, the leering and pawing figure of an Orc appeared before his eyes, representing Frodo's desire to possess the Ring. Earlier, Frodo's fantasy stemmed from the Ring's control. However, here, the fantasy resulted from Frodo's own mind. It indicated that Frodo has recognized the Ring's will, and he has been controlled by it.

Frodo's suspicion toward Sam meant he inwardly cut all connections with the outside world, and his ego fell into absolute loneliness. Therefore, in the end, although Sam insisted on accompanying Frodo, he never felt any warmth or any existence of life. He told Sam that, "At least, I know that such things happened, but I cannot see them. No taste of food, no feel of water, no sound of wind, no memory of tree or grass or flower, no image of moon or star are left to me. I am naked in the dark, Sam, and there is no veil between me and the wheel of fire. I begin to see it even with my waking eyes, and all else fades" (Tolkien, 1999, p.1226).

'Naked' is a materialized form representing a spiritual inanity. We can see that at an emergent point, Frodo has lost his ego and been controlled by the evil Ring. Therefore, on Mount Doom, Gollum, the dark side of Frodo, jumped up and knocked Sam out. At this moment, there was nobody to persuade Frodo. His trial of fleeing away with the Ring on his finger indicated his humanity had finally disappeared.

Through the subtle descriptions of the changes in the three hobbits' minds, the novel presents the process of humanity's loss. However, even though the Ring made their humanity unbalanced, they never gave up fighting against the Ring's control. 
According to the above description, we can see the characters suffer from many mental conflicts, namely the interaction of id, ego and superego, to change both social and personal conditions. Conflict is unavoidable and can sometimes be healthy, but unresolved conflict can thwart a person's ability to grow and develop. According to psychoanalytic views, psychological conflict is an intrinsic and pervasive part of human experience. Furthermore, the conflict between the id and the superego, negotiated by the ego, is one of the fundamental psychological battles all people face (Freud,1992, p.25). The ego usually acts as a mediator between the id and the superego. It is also the ego's job to satisfy the impulses of the id, but in a manner that fits reality to a particular situation. Since impulses are rarely realistically satisfied, it is the ego's task to keep them beneath the individual's awareness. It uses problem-solving skills to solve the conflict and anxiety between the id and the environment. However, when anxiety is so strong that it threatens to engulf the ego, defense mechanisms come into play.

\section{The ReAson for Degeneration: Material Desire}

The three hobbits' humanity was distorted because of the Ring's control. They strove to achieve the revival of humanity. Therefore, we can find that humanity's sublimation or degeneration was closely connected with the Ring. A closer analysis of the Ring can detail the reasons for this degeneration.

Like all other rings, the Ring was forged by human beings. It was ultimately an object with the attributes of an object. Nevertheless, it was different from a common object since it could deliver human beings' desires, indicating the worship of material desire.

The Ring was the creation of Sauron. When Sauron forged it, he endowed it with his evil will. This wickedness could tempt any person, causing them to have evil ideas. Isildur was the first who was tempted by the Ring. When Isildur cut the Ring from Sauron's finger, his heart was immediately controlled by the Ring. Then he changed his ideas and betrayed the oath of destroying the Ring, wanting to possess the Ring himself. Of course, he was doomed to fail. When Deagol found the Ring on the bed of the river, Gollum at once got the idea of killing his friend and taking possession of the Ring. Even Gandalf and Galadriel, who owned supreme power, became seduced by the Ring. To sum up, the Ring meant an object's incentive to human beings, and the reason why the Ring could have irresistible power was that it could fulfill people's desire, helping them attain that which they dream of. In the novel, the Ring had two kinds of temptations:

Freud holds the idea that instinct is an organism's impulse to return to an original situation. He divided instinct into two categories: life instinct and death instinct. Life instinct is also called sexual instinct, which is the internal motive for life's evolution and development (Wang, 1998, p.54-55). However, it happens in a casual manner. Death instinct is a born instinct and is life's essence and goal, which is inevitable.

Although humans have sensibly realized the inevitability of death, people were unwilling to face death. Therefore, the longing for immortality and the fear for death have constituted people's biggest trouble in the world. The greatest temptation the Ring brought was that it could help people resist death and live forever.

In addition to immortality, the Ring's temptation can be seen in its endowment of supernatural power. Letting people who wear the Ring become invisible is the Ring's most obvious characteristic. Invisibility enables people to be curious and different. It can also make people become lazy, representing the dark side of humanity. Because of the existence of the Ring, all dreams can be achieved easily, and may therefore degenerate easily. The Ring cannot bring happiness to people because it brings out people's personal desires. A mind filled with countless desires is doomed to fail. We can say people's desire to possess an object is the primary reason for their degeneration.

\section{Humanity's ReCOVERy: THE PuRsuit OF HaPPINESS}

The Ring's evil gives the three hobbits an imbalanced relationship between their inner urges and social demands. Achieving a stable state of mind is a key problem to be solved. The obvious solution is to change social or personal conditions. In fact, the characters did solve this problem in relation to these two aspects.

From Bilbo, Frodo, and Gollum's experience, we can see that their principally spiritual degeneration stems from the Ring's control. To find their humanity, a balanced mental state is vital to fight against the Ring's corrosive qualities. In the novel, Gandalf and Bilbo decided to leave the Ring with Frodo, thinking he has a healthy body and the virtues that would help him resist the Ring for a longer time. They knew he would ultimately fail, though. An inherent goodness is therefore a key weapon in fighting against the Ring.

From "Concerning Hobbits," we have some general knowledge regarding hobbits: "Hobbits are unobtrusive but very ancient people" (Tolkien, 1999, p. 1); "at no time had Hobbits of any kind been warlike, and they had never fought among themselves" (Tolkien, 1999, p.7). Moreover, they do not have government like humans do, which renders them less bound. Therefore, they can develop the purest and kindest personalities. As hobbits, Bilbo, Frodo, and Gollum also inherit these virtuous qualities. They are easily content, hard-working and strong-minded. Therefore, even though they have lost themselves to the Ring's erosion, they still can escape the Ring's control and find their humanity again.

When Bilbo obtained the Ring from Gollum, he did not lose his mind like Gollum, nor was he tortured by the Ring like Frodo. This was because he was kind and easily content, which allowed him to resist the Ring's temptation. In The Hobbit (Tolkien, 1999, p.1937), Bilbo, Gandalf and several dwarfs went on a journey looking for treasure. When they 
prevailed, the king of the dwarfs rewarded Bilbo with a large amount of gold. However, Bilbo refused to take it, saying that living peacefully and happily is more important. In the chapter "A Long-Expected Party," Bilbo's birthday party was a significant event in the Shire. All the Shire's people were invited to take part in the great feast and received a present, indicating that Bilbo lived a wealthy life. We can see that virtuous qualities and a wealthy life made him both materially and spiritually satisfied. This satisfaction allowed him to not be easily controlled by the Ring, which has not left many marks on Bilbo. Although Bilbo realized the Ring presented an unmistakable burden, he never lost his mind like Gollum, who always wanted to possess the Ring. He finally decided to have a quest in the forest, and left the Ring with his heir, Bilbo. On his journey, his normal humanity finally returned.

Frodo was Bilbo's heir. He was the last to obtain the Ring as an inheritance and he undertook a historical mission with it. Like Bilbo, Frodo had a kind, agreeable personality, which made him popular among the Shire's people. In the council of Elrond, when considering Frodo's virtues, the king of the elves, Elrond, insisted on selecting Frodo as the Ring-bearer to destroy the Ring. When almost all present suspected Frodo's ability, Elrond stated that, "this quest may be attempted by the weak with much hope as the strong. Yet such is oft the course of deeds that move the wheels of the world: small hands do them because they must, while the eyes of the great are elsewhere" (Tolkien, 1999, p.351). It was Frodo's hobbit toughness that enabled him to resist the Ring's control and finish the great mission. Ever since Frodo put the Ring on and left the Shire, the Ring tried to make Frodo surrender, while Frodo made every effort to resist the Ring's attrition. Therefore, all throughout the journey to Mount Doom, Frodo's heart was interwoven with compassion and wickedness.

The contrast of compassion and evil in Frodo's mind also presented itself in the form of Gollum and Sam, the characters who followed Frodo all the way from the Shire to Mordor. When Frodo finally destroyed the Ring, the two characters both influenced Frodo. Sam acted in the compassionate role, while Gollum played the evil role. Therefore, the objective of destroying the Ring was achieved due to all three characters' efforts. Without Gollum and Sam's help, Frodo would never have completed his quest.

In Elrond, Gollum was presented as a shadow between Frodo and Bilbo. Tolkien used Gollum as the shadow aspect of Frodo, indicating that the two had an intimate relationship. However, Gollum was the externalization of Frodo's shadowy personality. From the plot, we can see Gollum was present or otherwise in a manner that reflected the changes in Frodo's mind. As soon as Frodo left the Shire, Gollum began to follow him. Readers never see the presence of Gollum, only finding his blurry image in the words, until they passed into Mordor. We can notice that Frodo's shadow was strong or light depending on whether Gollum was present or hidden. Before leaving the Shire, Frodo's mind enjoyed peace. After leaving the Shire, Frodo's mind began to gradually change under the influence of the Ring. When entering Mordor, with the Ring's temptation increasing steeply, and Frodo's resistance decreasing strongly, Frodo finally gave in to the Ring, and his moral character diminished by trying to put the Ring on and presenting himself before the evil eye. Therefore, Gollum was the externalization of Frodo's evil power.

On the contrary, Sam, who had accompanied Frodo ever since they left the Shire, represented the kind aspect of Frodo. The Ring's most dangerous element was that it could corrode a human being's soul and estrange relationships between people. The conflict between Boromir and Frodo on Mount Amon Hen was due to the Ring's influence. When Frodo put the Ring on and became invisible, Boromir shouted, "Frodo, Frodo! Come back! A madness took me, but it has passed. Come back" (Tolkien, 1999, p.521). However, Sam, who had accompanied Frodo the longest, did not change at all and always preserved the virtuous qualities of hobbits. Tolkien wrote that Sam was "a reflection of the English soldier, of the privates and batman I knew in the 1914 war, and recognized as so far superior to myself" (Carpenter, 1981, p. 91). Therefore, the author endowed Sam with admirable qualities and power. During their journey to Mordor, Sam not only prepared Frodo's meals but also acted as Frodo's spiritual support. Every time Frodo fell into spiritual crisis, Sam would provide Frodo with the capacity to pass through the crisis and could always aid Frodo when he went into a "spiritual wasteland."

"The one Ring was endowed the power of ruling all the world by the Dark Lord. All things in Middle-earth are affected by its magic and evil power, but Tom in the Old Forest was an exception. When Frodo put on the Ring and was invisible in front of Tom, he found that the Ring lost its power. Old Tom was an incarnation of nature. That the Ring lost its power before old Tom meant that nature could also help to resist the Ring's evil power. In the process of destroying the Ring, the spiritual power given by nature also enabled the characters to escape being turned into a creature without humanity. Nature's influence can generally be divided into three aspects:

Nature is the place full of life and the real-world, possessing divinity. The reminiscence of nature is the call of beauty and the dream of divinity. However, beauty and divinity are vital factors in human beings both obtaining and retaining humanity. Therefore, the reminiscence of nature can draw Frodo and Gollum back from degeneration.

Gollum has lived in the cavern for several centuries with the Ring at hand. During this extensive time, although the Ring had the upper hand in Gollum's mind, it could not totally change him. In addition to Gollum's dogged life and sturdy defensive qualities, the recall of nature also secretly supported Gollum's mind. Gandalf said that, "Even Gollum was not wholly ruined. He has proved tougher than even one of the Wise would have guessed — as a hobbit might. There was a little corner of his mind that was still his own, and light came through it, as through a chink in the dark: light out of the past. It was actually pleasant, I think, to hear a kindly voice again, bringing up memories of wind, and trees, and sun on the grass, and such forgotten things" (Tolkien, 1999, p.72). "Was not wholly ruined" means that there remained 
some conscience in Gollum's mind that had not been engulfed. "Light came through his mind" indicates that a recall of nature helped Gollum insist on not being controlled by the Ring.

As for Frodo, it was the recall of nature that supported him along the journey through Moria. The days when Frodo was tied up and tortured on the tower of Cirith Ungol were dark indeed, and the recall of nature supported Frodo throughout these perils. When Frodo lost hope of destroying the Ring, he responded gloomily to Sam that, "At least, I know that such things happened, but I cannot see them. No taste of food, no feel of water, no sound of wind, no memory of trees or grass or flower, no image of moon or star are left to me. I am naked in the dark, Sam, and there is no veil between me and the wheel of fire. I began to see it even with my waking eyes, and all else fades" (Tolkien,1999, p.1226). Frodo forgetting about nature indicates that Frodo had lost the last pure aspect of his mind and had become totally controlled by the Ring. "Naked" represents a materialized presence alluding to a spiritual emptiness. It suggests that Frodo had rendered his soul to the dark lord and only his body remained in the world. Therefore, like Gollum, he could not think of anything living. Nature was the last protective screen between them and the dark lord. Once they lost the protection of nature, they would fall into the dark abyss.

In the novel, salvation was also demonstrated at the places of Elrond, Lothlorien, and the High Sea. The three were all dwellings of elves. They are utopias created by Tolkien and represent perfect worlds that humans long to dwell in. The three spaces are filled with nature's beauty and healing power, so the Ring's power is restrained here, and Frodo's humanity is retained. The subsequent section portrays and explains how this healing power is achieved.

Frodo was wounded by Strider's sword on Weathertop. He would not die, but he was controlled by the dark lord's evil will. "He almost welcomed the coming of night, for then the world seemed less pale and empty" (Tolkien, 1999, p.277). "Then Frodo felt himself falling, and the roaring and confusion seemed to rise and engulf him together with their enemies" (Tolkien, 1999, p.281). Moreover, Frodo's arm became slightly transparent, which indicates his empty mind. Frodo's abnormal behavior in Elrond is caused by this, so Frodo's recovery in Elrond represented his spiritual recovery. As Tolkien described in the novel, "Elrond has a magic power, not long before, all anxious and fear would disappear from their mind." When Bilbo left the Shire and went on his journey, he lived for a long time in the Shire, and he gradually gained a peaceful mind, having a happy life there. He almost escaped the Ring's control, so when he saw the Ring again, he no longer lost his mind as he did before. He just received the Ring in a peaceful manner. Blbo's devastated heart was cured in Elrond.

Lothlorien is a place full of beauty, goodness, and truth. Elves who live here worship it, so here is retained the purest and most beautiful scenery in the whole of Middle-earth. Walking through this fantastic dream-like world, Frodo's heart was shocked. Legolas said, "the sound of the falling water may bring us sleep and forgetfulness of grief" (Tolkien, 1999, p.441). Fascinated by its extreme beauty, Frodo would leave his heart in Lothlorien, which indicated that his heart was purified by nature, gaining salvation. Therefore, when the companions all received tests from Galadriel, the Lady of Lorien, all except Frodo experienced a dilemma. The other people wanted to choose, meaning their hearts were not strong enough to resist seduction. That Frodo could ignore Galadriel's temptation meant he already had the ability to fight against the evil Ring, his behavior having changed considerably since he walked into Lothlorien. Before going into the forest, he was tempted on four occasions. He resisted the Ring's temptation only once, because of the elf's song. The other three times he was subjected to temptation, he put the Ring on and went into the world controlled by the dark lord. When Frodo recovered, he felt loneliness for the first time, which estranged his fellowship. When he walked out of Lothlorien, he had developed the power to resist the Ring until it was destroyed at last. Therefore, we can see that Lothlorien, the embodiment of nature, endowed Frodo with the power of retaining his virtue and fighting against the malevolent Ring's control.

When the Ring was destroyed by the fellowship, all were happy. However, Frodo was upset about returning to his previous life. The Ring had clearly done great harm to Frodo's mind, which could not be cured. Back in the Shire, Frodo was always sick, and his mind was withered. When Sam tried to persuade Frodo stay in the Shire, Frodo said, "'Sam, when things are in danger: someone has to give them up, lose them, so that others may keep them. [..]Your hands and your wits will be needed everywhere. "come now, ride with me"” (Tolkien, 1999, p.1347). Sam chose to stay in his beloved Shire and arranged to sail to the West in order to sooth Frodo's injured soul. In western cultures, a boat can bring people to another world, so it implies Frodo's sublimation of the mind.

A crystal phial and earth from Lorien were given to Frodo and Sam as presents. Because these presents came from a divine world, they were endowed with great power from nature. Therefore, these two presents played an important role in the novel.

Mirrors are used by human beings to judge themselves. Because of its special function, a mirror usually plays the role of recognizing both human beings and the outside world. The Mirror of Galadriel is a galactic disk with divine water in it. It can not only tell the past, present, and future of those who stare at its surface, it can also reflect people's minds, helping them find and know their egos. As the queen described, "in this phial is caught the light of Earendil's star, set amid the waters of my fountain. It will shine brighter when night is about you" (Tolkien, 1999, p.491). In this sense, the crystal phial is not only a tool but also an embodiment of nature.

The earth given by Galadriel to Sam helped when reconstructing the Shire. When Frodo and his hobbit friends returned to the Shire a long time after they left it, they found that the Shire had significant negative changes. Life there had become complicated. Its people had lost faith in and kept away from others. To Frodo's dismay, in the Shire stood 
great numbers of factories, many forests were cut down, rivers emitted foul smells. In order to retain the Shire's old beauty, Frodo and his friends undertook many actions. However, like Frodo's heart, the Shire could not regain its old scenery. Therefore, Sam brought out the earth to bring the Shire back to life. The dust given by the elf was filled with nature's power. It could make the soil regain its vitality. "His trees began to sprout and grow, as if time was in a hurry and wished to make one year do for twenty[...] an that flicker and pass upon this Middle-earth" (Tolkien,1999, p.1339). "Mud" is the root of life and the continuance of it. The sprouting of Lorien's earth in the Shire suggests that hobbit culture will continue in the Shire through the healing spirit of nature's divinity. Therefore, because nature recovered its original appearance, the hobbits also retained their virtues.

To sum up, although the three hobbits who were closely connected with the Ring were tormented and tempted by its evil spirit, they strove to make their egos mediate between their ids and superegos to obtain perfect personalities. The happiness of the novel's ending lies in it illustrating that decent people will finally receive a happy life if they adhere to goodness and tenacity.

\section{REFERENCES}

[1] Freud, Anna. (1973). The Ego and the Mechanisms of Defense V01.2.New York, International University Press, Inc.

[2] Henk de Berg. (2003). Freud's Theory and Its Use in Literary and Cultural Studies: an Introduction: New York, Camden House.

[3] Harold Bloom. (2008). Bloom's Modern Critical Views: J.R.R.Tolkien, New Edition: Infobase Publishing.

[4] Trans. Joan Riviere. Rev.ed. James Strachey. (1962). Sigmund. The Ego and the Id. New York, W.W. Norton and Company.1nc.

[5] Tolkien, J. R. R. (1999). The Lord of the Rings: Great Britain, Harper Collins Publishers Ltd.

[6] Wang Yuechuan. (1998). Literary Theory of Psychoanalysis. Jinan: Jinan Education Press.

[7] Yang Huayu. (2000). An Elementary Textbook of Psychoanalysis. Beijing: Beijing Press.

Lili Liu was born in Taian, China in 1987. She received her Master's degree in English literature from Sichuan International Studies University, China in 2015.

She is currently a lecturer in the School of Foreign Languages, Taishan University, Taian, China. Her research interests include English teaching methods and English literature. 